\title{
Pedra e palavra: patrimônios culturais e formação de professores
}

\author{
Cyntia Simioni França* \\ Nara Rúbia de Carvalho Cunha** \\ Guilherme do Val Toledo Prado ${ }^{* * *}$
}

\begin{abstract}
Resumo
O presente texto apresenta duas pesquisas em nível de doutoramento que se desdobraram em pesquisas-ação de formação docente,compostas por professores de Educação Básica de escolas públicas de Londrina-PR e Ouro Preto-MG, nas quais foi tematizada a relação entre produção de conhecimentos histórico-educacionais e experiências vividas, tendo em vista a formação docente, abordando patrimônios culturais (O Canto da Odisseia e a cidade de Ouro Preto) como meios de reflexão. O referencial teórico-metodológico e a análise dos dados foram desenvolvidos no interior dos grupos e Kairós, sediados respectivamente na Faculdade de Educação e no Centro de Memória, ambos da Universidade Estadual de Campinas, em Campinas-SP.

Palavras-chave: Formação docente; experiência; memórias; patrimônios culturais; narrativa e cidade.
\end{abstract}

\section{Stone and word: cultural heritage and teacher training}

\begin{abstract}
This paper presents two studies at doctorate level which are developed as research-actions of teacher training, composed by Basic Education professors of public schools from Londrina-PR and Ouro Preto-MG, whose the theme was the relationship between the production of historical-educational knowledge, focusing on the teaching training, and the actual experiences, bringing cultural heritage (the Song of the Odyssey and the city of Ouro Preto) as means of reflection. The theoretical-methodological referential and the data analysis were developed within the GEPEC groups -and Kairós, based respectively in the Faculty of Education and in the Memory Center, both part of the State University of Campinas, in Campinas-SP.
\end{abstract}

Keywords: Teacher training; experience; memories; cultural heritage; narrative and city.

\section{Introdução}

Em fevereiro de 2012 iniciamos duas pesquisas de formação docente junto ao programa de Pós-Graduação em Educação da Faculdade de Educação da Universidade Estadual de Campinas, em Campinas-SP, no interior do GEPEC - Grupo de Estudos e Pesquisas em Educação Continuada e em diálogo com o grupo Kairós: educação das sensibilidades, história e memórias, sediados respectivamente na Faculdade de Educação e no Centro de Memória, ambos dessa mesma Universidade.

O GEPEC existe desde $1996^{1}$ e é atualmente coordenado pelo professor Guilherme do Val Toledo Prado. Ao longo desses anos, suas pesquisas têm se destacado no meio acadêmico e escolar por serem protagonizadas por professores/educadores que investigam sua própria prática em seus ambientes de trabalho, ou seja, elas não são sobre professores e educadores, mas com eles e deles; do mesmo modo, tais pesquisas não são sobre o ambiente escolar, mas na escola, da escola, com a escola. O Grupo tem sido espaço privilegiado para aprofundar a produção de conhecimentos e saberes na escola e na universidade, fomentando estudos e pesquisas de e com profissionais da educação. Nesse sentido, desenvolve-se um projeto coletivo de formação, fundamentado em uma epistemologia transgressora, subsidiada nas reflexões das práticas evidenciadas nas narrativas pedagógicas produzidas pelos professores e profissionais participantes nos contextos de produção na e da escola (CORTESÃO, 2004; GERALDI et al., 1998).

Entre os caminhos metodológicos mais comumente empregados pelos pesquisadores do GEPEC estão as pesquisas narrativas, com diferentes abordagens ${ }^{2}$ e, geralmente articulada a estas últimas, a pesquisa-ação. Mikhail Bakhtin, Walter Benjamin, Lev Vygostsky e Paulo Freire compõem os principais referenciais teóricometodológicos do Grupo.

O Kairós, apesar de ser um grupo de

\footnotetext{
* Endereço eletrônico: cyntiasimioni@yahoo.com.br

** Endereço Eletrônico: nrcalegria@gmail.com

**** Endereço Eletrônico: gvptoledo@gmail.com
} 
pesquisas mais recente, tem uma trajetória de investigação que lhe antecede e dá origem, com pesquisas realizadas e orientadas pela professora Dra. Maria Carolina Bovério Galzerani, as quais têm em comum o referencial teórico-metodológico composto, sobretudo, por Walter Benjamin, Eduard Palmer Thompson e Peter Gay. Embora haja entre essas pesquisas uma diversidade de ambientes e sujeitos de investigação, os processos de educação política dos sentidos as perpassam como objeto ou tema de investigação, do mesmo modo que as memórias e o trabalho com as memórias - mais frequentemente os trabalhos de rememoração coletiva - estão presentes também como objeto, tema e caminho metodológico de pesquisas que visam a colaborar com os campos da História e da Educação (GALZERANI, 1998; 2004; 2008; 2013a).

As pesquisas aqui focalizadas foram orientadas pela professora Dra. Maria Carolina Bovério Galzerani ${ }^{3}$ até fevereiro de 2015, quando passaram para orientação do professor Dr. Guilherme do Val Toledo Prado. O projeto O Canto da Odisseia e as Narrativas Docentes foi desenvolvido em nível de doutoramento pela professora-pesquisadora Cyntia Simioni França por meio de uma pesquisa-ação de/com professores de Educação Básica, lotados em escolas públicas de Londrina-PR. Do mesmo modo, Primaveras Compartilhadas foi desenvolvido pela professorapesquisadora Nara Rúbia de Carvalho Cunha, também em nível de doutoramento, desdobrando-se em uma pesquisa-ação com professores de educação básica, lotados em escolas públicas de Ouro PretoMG.

À parte as especificidades de cada projeto, as duas pesquisas preocupavam-se com à relação entre experiências vividas e docência, imbricando questões pertinentes aos grupos de pesquisas nos quais nos inserimos. Nessa perspectiva, os bens culturais tomados como propulsores das discussões não se limitaram à condição de monumentos, o que muitas vezes promove a criação de um campo aurático que distancia sujeitos e objetos e, portanto, dificulta a percepção dos sujeitos na relação com os bens culturais ou, dito de outra forma, os sujeitos não conseguem articular seus patrimônios às suas experiências (CHOAY, 2006; BENJAMIN, 1994).

Como a inserção do tema pesquisado no cenário de seu engendramento histórico é um traço característico das produções de conhecimento do Kairós, nossos projetos refletiam sobre a formação docente na modernidade capitalista, diante do prevalecimento de relações sociais esfaceladas, alicerçadas nas hierarquizações dos saberes e dos sujeitos; relações que negam o outro, o diferente, e que promovem, inclusive, o apagamento de nós mesmos, porque "reproduzimos, muitas vezes, o universo simbólico do sempre igual" e "construímos visões históricas, educacionais, homogeneizadoras, apagadoras das diversidades socioculturais, distantes das nossas experiências" (GALZERANI, 2004, p. 290).

Tanto no projeto o Canto da Odisseia e as Narrativas Docentes quanto em Primaveras Compartilhas, partimos da noção de experiência alicerçada em Thompson, enquanto visões de mundo, sensibilidades e saberes plurais constituídos no cotidiano, numa arena de lutas, de tensões e resistências e que, portanto, negam os determinismos, uma vez que "as maneiras pelas quais qualquer geração viva, em qualquer 'agora', 'manipula' a experiência desafiam a previsão e fogem a qualquer definição estreita de determinação" (THOMPSON, 1981, p. 189).

Ainda de acordo com esse autor, a experiência é excluída do campo da educação liberal, que mais pretende moldar o outro do que produzir conhecimentos de forma dialógica (THOMPSON, 2002). Nesse sentido, ao negar a experiência, negam-se os conflitos, os outros, os diferentes; nega-se, por sua vez, a incompletude, a abertura para o incerto, para o não previsto e não determinado.

Portanto, buscamos com nossas pesquisas colaborar com o debate sobre a formação docente, na contemporaneidade, a partir desse problema que se configura com a separação entre experiência e educação, nesse caso, formação.

As reflexões de Walter Benjamin, por sua vez, nos colocaram o problema do declínio da experiência na modernidade. Nesse caso, a experiência é compreendida enquanto conhecimento elaborado no coletivo, na relação com o outro, no intercâmbio do vivido, no ritmo do trabalho artesanal que permite a lenta sedimentação do que é percebido. Essa experiência (erfahrung) estaria em declínio na modernidade, na qual predomina a vivência (erlebnis) do homem isolado, submetido a constantes choques, mas cujas percepções são imediatas e não se desdobram em visões outras (BENJAMIM, 1989; 1994).

Nos textos "O Narrador" e "Experiência Pobreza" (BENJAMIN, 1994), Benjamin nos alerta sobre o desaparecimento da experiência na modernidade concomitante ao declínio da narrativa 
tradicional. $\mathrm{O}$ autor compreende que, com o avanço do capitalismo, esgarça-se a vida coletiva, o respeito às experiências dos anciãos, bem como a cadeia temporal. Passa a prevalecer, então, a vivência, modo que leva ao despojamento da imagem de si e do outro e à perda gradativa da memória, visto que o passado deixa de ser referência de continuidade e os sujeitos são atropelados pelo tempo do relógio.

Se o que tem sido reforçado com o declínio das experiências ou da faculdade de intercambiá-las é uma "individualidade, construída socialmente como modelo", na qual não reconhecemos nem a nós mesmos nem ao outro (GALZERANI, 2005, p. 65), até que ponto deixaremos as experiências serem extintas de nosso cotidiano?

Convivemos com a marginalização de nossas experiências, como nos fala Thompson, e com o declínio da experiência enquanto saber intercambiado, constituído no coletivo. Em nossas vivências profissionais cotidianas estamos sempre submetidos a currículos pré-estabelecidos distantes de nossas realidades locais; somos sempre apagados em nossas especificidades, em detrimento de uma formação generalizante. Portanto, como docentes, compreendemos a importância da luta do GEPEC por uma formação que faça frente ao crescente desrespeito aos saberes constituídos na docência ou fora dela. $\mathrm{Na}$ interface com os dois grupos de pesquisa, como docentes, podemos atestar a necessidade de uma pesquisa que incorpore à imagem de professor os tantos outros que nos habitam.

Ao tratar de experiência num sentido lato, acreditamos para além das noções mais corriqueiras de habilidade adquirida na constância da prática ou de experimento científico, sem, contudo, desconsiderá-las. Retomamos as noções de experiência, tanto de Thompson quanto Benjamin, atentos aos problemas que elas nos trazem para pensarmos a formação docente na contemporaneidade, para compreender a formação em um espaço-tempo alargado e trazer o docente em sua pessoalidade mais inteira, isto é, procuramos ver o docente não apenas do ponto de vista da formação acadêmica, não apenas em sua dimensão racional, não apenas consciente, mas também um ser atravessado por saberes de diferentes naturezas, de emoções e de memórias de dimensões conscientes e não conscientes.

Para tanto, imprimimos em nossas pesquisas um caráter investigativo-reflexivo que trabalhava com o entrecruzamento de temporalidades e o intercâmbio do vivido por meio de partilhas de narrativas e rememorações coletivas desencadeadas pela leitura da obra literária Odisseia, no grupo de Londrina, e pela tematização de nossa inserção na cidade, no caso do grupo de Ouro Preto.

A pedra (cidade) e a palavra (literatura), ambos patrimônios culturais, favoreceram a produção do conhecimento histórico educacional na articulação com as experiências dos sujeitos porque foram abordados de forma alegórica, como convite à ressignificação; uma ressignificação que não envereda por polos extremos da subjetividade ou da objetividade. Não foi a obra literária ou a cidade que definiram o processo de formação de professores, mas as possibilidades de conexões e relações reflexivas que se constituíram como formativos, tendo em vista que nossas sensibilidades se (trans)formam na interação com os bens culturais.

Se pedra e palavra podem ser vistas como objetos de educação de corpos, sentidos e ideias como comumente se observa em práticas de memória que privilegiam o apagamento dos sujeitos em função da promoção dos objetos, como é caso das cerimônias e comemorações cívicas ou da construção de heróis e símbolos nacionais (SILVA, 2002) - elas também podem ser assumidas, nas práticas educativas e de memória, como abertura para um dizer outro, alicerçado nas experiências singulares (GALZERANI, 2013a). Nesse sentido, propusemos uma reflexão ampliada, ou seja, para além da visão restrita de patrimônio como monumento, pensando nas possibilidades que ele nos oferece para a produção de conhecimentos histórico e educacional por um viés coletivo e dialógico, quando tomado como meio de reflexão. Fomentamos a aproximação dos sujeitos com os objetos (bens culturais) em movimentos que pudessem deslocar tais objetos do viés monumental e atualizador de sentidos previamente definidos, apostando em práticas de memórias baseadas na rememoração coletiva, abertas ao inaudito.

Numa acepção benjaminiana, as memórias são compostas por amálgamas de experiências. Segundo Benjamin (1985), elas abarcam dimensões voluntárias e involuntárias, de lembrança e de esquecimento. Portanto, podemos buscar acessá-las de forma vigiada, direcionada, como quem busca resgatar algo preciso, ou podemos escavar como um arqueólogo, inventariando o que se procura e o que se faz encontrar. Assim, um processo de rememoração é de escavação constante; ele nos permite acessar uma multiplicidade de experiências individuais tecidas no coletivo e com as quais podemos estabelecer correspondências. 
O trabalho com as memórias foi bastante empregado pela professora Maria Carolina em projetos de formação docente (GALZERANI, 2004; $2008 \mathrm{a} ; 2013 \mathrm{a} ; 2013 \mathrm{~b}$ ), porque ela concebia as memórias como palco de expressão de experiências vividas e meio de questionamento de sensibilidades historicamente constituídas, na esteira do filósofo Walter Benjamin. Dessa forma, seu trabalho se empenha em articular os achados das rememorações à macro história, com o intuito declarado de não permitir que os sujeitos percam a crônica de si mesmos, isto é, deixem de se reconhecer como sujeitos historicamente constituídos em relações tensas e conflituosas, das quais são também protagonistas.

Portanto, as rememorações aqui fomentadas buscaram instigar a elaboração de crônicas singulares - no diálogo com outros sujeitos e com bens culturais que estão, de alguma forma, vinculados às nossas experiências - sem perder de vista que nos inserimos em uma história mais ampla, a qual tem fomentado o silenciamento de vozes plurais e o apagamento de marcas singulares. É nesse sentido que questionamentos a forma como lidamos com o nosso patrimônio cultural e a própria docência, em ambas as pesquisas.

\section{Primaveras compartilhadas}

Desde a elaboração do projeto inicial, era proposta do Primaveras Compartilhadas a formação de um grupo de professores que pudesse realizar um trabalho coletivo, na interface com o espaço urbano, mobilizando memórias e linguagens na investigação coletiva de nossas sensibilidades (docentes).

$\mathrm{O}$ projeto começou a ser definido ainda no mestrado, quando, sob a orientação da professora Maria Carolina, pesquisamos o Museu-Escola do Museu da Inconfidência, em Ouro Preto-MG, na década de $1980^{4}$, e percebemos que havia naquele período um trabalho de formação docente concomitante ao trabalho educativo com as crianças, jovens e adultos que participavam das ações educativas do Museu-Escola. Então, incialmente, a ideia era continuar investigando aquele trabalho.

No entanto, nos anos de 2010 e 2011, nós professores do estado de Minas Gerais vivemos duas greves no contexto de campanhas a favor da implantação do Piso Salarial Profissional Nacional para professores (Lei 11.738, de 16/07/2008), promovidas pelo Sindicato Único dos Trabalhadores em Educação de Minas Gerais (Sind-Ute/MG), que tiveram desdobramentos significativos em nossas carreiras docentes. Além de termos nossos salários convertidos em subsídios, sofremos, por exemplo, a perda das gratificações bianuais e quinquenais, o que representava não apenas perdas econômicas e de direitos conquistados em outras lutas, mas também uma violência simbólica, porque retirava de nossos contracheques uma marca de nossa experiência adquirida ao longo do tempo de trabalho, tirava de nossas carreiras a sua história.

Contudo, apesar dos desdobramentos havidos, aquele longo período de greve $\mathrm{e}^{5}$ com as constantes manifestações, reuniões e debates promovidos pelo Sind-UTE/MG, tanto no pátio da Assembleia Legislativa em Belo Horizonte quanto nas cidades do interior do estado - permitiu que nós professores nos aproximássemos uns dos outros de uma forma até então inviável, em função das grandes cargas horárias de trabalho de pessoas que, geralmente, acumulam dois ou mais cargos, em diferentes escolas.

Em nossos encontros, começamos a nos perceber em condições muitos semelhantes, isto é, com vivências e, quiçá, experiências comuns. Passamos, de certa forma, a nos reconhecermos no outro de uma maneira que transcende o discurso generalizante de nossas condições. $\mathrm{O}$ que de fato percebíamos era que comungávamos tanto da desvalorização profissional quanto de sensibilidades humanas que vão além dos limites da escola, embora lá também se façam presentes. E foi nesse contexto que resolvi mudar o projeto que estava elaborando, abandonando a ideia de continuar pesquisando o Museu-Escola para me lançar ao desafio de uma investigação conjunta, ao lado dos meus colegas de profissão, tematizando a constituição de nossas sensibilidades no emaranhado de experiências que nos formam.

Atentos às pesquisas do Kairós e do GEPEC, procuramos promover um movimento de partilha que nos permitisse investigar nossas experiências em diferentes tempos e espaços, na relação com muito outros que nos habitam, nos marcam, nos (com/trans)formam. Escolhemos fomentar as reflexões do grupo tendo o ambiente urbano, a cidade, como meio de investigação.

Ouro Preto, por ser um Monumento Nacional e Patrimônio Histórico e Cultural da Humanidade é sempre objeto de ações educativas, estudos de meio, visitas escolares de grupos vindos de diferentes cidades e países. Nós docentes que lá trabalhamos somos constantemente cobrados a incluirmos a cidade, em especial sua 
monumentalidade, em nossos planos de aula. Os dias, 21 de abril, no qual se homenageia o herói nacional Tiradentes, e 7 de setembro, em que se comemora a Independência do Brasil, são dias letivos com programação definida: levar os alunos à Praça Tiradentes, para assistirem às solenidades de transferência simbólica da capital mineira para Ouro Preto, no dia 21, e o desfile cívico da Independência, em setembro. As instituições culturais e educativas e até mesmo as empresas que se instalam na cidade também costumam incentivar ou promover ações de educação patrimonial, algumas até mantendo projetos próprios, como a mineradora Vale.

A cidade ainda é rica em movimentos e festivais culturais, de cinema, literatura, música e variedades para os quais as escolas são frequentemente convidadas, bem como para as programações periódicas de suas treze instituições museológicas.

Dessa forma, para qualquer professor de Ouro Preto, a cidade é um elemento a se considerar quando falamos de formação docente.

No entanto, a contrapelo das tendências dos cursos de "capacitação" e "reciclagem" que nos tornem aptos a incluir a cidade em nossas atividades docentes como um monumento a ser visitado e interpretado, quisemos promover uma investigação das nossas relações cotidianas com a cidade, tomando-a como espaço-tempo de formação de sensibilidades na modernidade capitalista (BENJAMIN, 2006); como ambiente que se reveste das dimensões de refúgio, território e selva, na, da e com a qual se aprende (MEIRIEU, 2008) e tomando-o como espaço que abriga diferentes camadas de tempo, diferentes memórias (CAUQUELIN, 1982), as quais, não raro, estão marginalizadas e em tensão com as memórias prevalecentes e reafirmadas nos ritos e monumentos.

Partimos de indagações sobre como o espaço urbano contribui para a formação de sensibilidades dos docentes ou como se configuram nas experiências dos docentes as sensibilidades modernas. Mais do que tomar a cidade como tema para um estudo de formação, buscávamos nos compreender nesse espaço-tempo urbano, acreditando que a investigação de nossas sensibilidades poderia nos ajudar a compreender a nossa condição enquanto sujeitos constituídos coletivamente, na relação com outros sujeitos, não apenas os nossos contemporâneos, mas também aqueles que nos precederam ou nos sucederão.
Assim, a opção pela cidade nos convidava a nos compreendermos enquanto sujeitos historicamente constituídos, que estão em constante diálogo com marcas (urbanas) da humanidade, ao mesmo tempo em que produzimos nossas marcas e as legamos aos outros (MEIRIEU, 2008; GALZERANI, 2004; 2013a).

Para potencializar a proposta, que se beneficiava de lições aprendidas também com o Museu-Escola, isto é, de uma formação continuada que ocorre no ambiente museológico, buscamos o apoio do Museu Casa Guignard, em Ouro Preto, o qual possui um sólido programa educativo que tematiza a paisagem urbana e nossa relação com a mesma. Depois de estabelecer a parceria, distribuímos convites para todas as escolas públicas da cidade e conseguimos formar um grupo composto por professores de Educação Básica, lotados em escolas públicas da cidade, os quais assumiram nomes de flores como pseudônimos: Cattleya, Orquídea, Girassol, Maria-sem-vergonha, Margarida e Flor de Lótus. Gélcio Fortes, artista plástico diretor do Museu Casa Guignard e nós, Nara Rúbia de Carvalho Cunha, coordenávamos as atividades e delas participávamos, enquanto a professora Dra. Maria Carolina Bovério Galzerani as supervisionava.

Entre maio de 2012 e maio de 2013 esse grupo de professores, que também se quis intitular Primaveras Compartilhadas, reuniu-se quinzenalmente no Museu Casa Guignard para participar de atividades diversas, tais como passeios pela cidade, observações da paisagem; oficinas de desenho e de fotografia, interação com acervos de espaços museais; visitas e montagem de exposições, além de leituras de textos científicos e literários; participação em rodas de conversa, oficinas e palestras com convidados vindos de outras instituições de pesquisa, museus e arquivos históricos; piqueniques em parques públicos e adros de igrejas e, finalmente, partilhas de experiências, por meio de rememorações coletivas e narrativas de cunho subjetivo e memorialístico, quase sempre desencadeadas durante as atividades.

É certo que cada professor trazia suas questões e motivações para participar do Primaveras Compartilhadas, assim como nós. No entanto, nesse percurso conseguimos entrecruzar perspectivas e nos ajudar mutuamente. Refletimos sobre nós mesmos como cidadãos, como professores, como alunos, como pesquisadores e conseguimos perceber o quanto ocupamos a cidade de forma parcial, fragmentária, como nos fala Anne Cauquelin: 
[...] a despeito de nós mesmos - vivemos nossos espaços do modo como ocupamos nossa história de vida, fragmentariamente, com esquecimentos e lacunas, sob a pressão de um estoque de opiniões do qual ignoramos a origem e só recolhemos o resultado, fina película que serve de tela e de suporte para a vida social (CAUQUELIN, 1982, p. 27. Tradução nossa).

Assim, uma fina película da história dessa cidade se impõe como memória dominante, excluindo sujeitos, memórias e experiências outras. Mas no movimento investigativo que realizamos, escavamos camadas de tempo, exploramos espaços ainda não visitados e promovemos um deslocamento de nossas zonas de conforto.

Ao longo de um ano de atividades, várias narrativas verbais, verbo-visuais e visuais foram produzidas pelo grupo de professores. Entre as narrativas dos professores, figuraram com destaque aquelas sobre memórias de experiências urbanas. Em tais elaborações a cidade foi revisitada, em outros tempos e espaços, trazendo à tona experiências singulares, que conferiam sentidos plurais às ruas, praças, manifestações culturais e edificações que compõem o tecido urbano, algumas, inclusive, ícones do patrimônio cultural tombado. Diferentes formas de percepção do tempo também vieram à baila e permitiram problematizar os ritmos de interação com a cidade, desde a cidade museu ou obra de arte, símbolo do Barroco mineiro, à cidade dos afazeres cotidianos, em crescente modernização.

Dessa forma, as rememorações se configuraram como possibilidades de estranhamento, como questionamento de sensibilidades, de imagens engessadas. Afinal, que cidade é essa, para além de sua dimensão de monumento e mercadoria, comercializada em cartões postais e souvenirs, sobretudo a partir da década de 1980, quando é tombada pela UNESCO como Patrimônio Histórico e Cultural da Humanidade? Que outras experiências, que outras memórias ela guarda em diferentes camadas de tempo estratificadas nesse espaço?

Destaco aqui fragmento de uma narrativa dos professores, a fim de focalizá-lo de forma monadológica (BENJAMIN, 1984; GALZERANI, 2013c), isto é, como centelha dos sentidos que perpassam todo o conjunto.

Quando a cidade me toca ou como sou tocada pela cidade? Pergunta capciosa essa, não? A mente divaga... Mas as imagens surgem e acumulam-se, formam-se quadros, flashes... cheiros... gostos ... sons... saudades!!

Manhã com brumas em Ouro Preto, este quadro, pintura cinza com raios dourados apolíneos, toca-me com leveza e fresca trazendo esperança, paz.

A imagem da minha mãe na casa velha do Antônio Dias em sua velha cozinha, o "cuador" de pano e o cheiro de café recém-feito. Assim, a cidade toca-me.Manhã de brumas meu velho pai descendo a ladeira de Santa Efigênia, cantando "Boemia", toca-me.Festa de Santa Efigênia, sinos festivos anunciando a princesa Núbia, toca-me e me acaricia, torno-me novamente criança nos braços carinhosos de minha vó. Sinos da Matriz de Nossa Senhora da Conceição nos domingos pela manhã, como anjos anunciando Maria a nos cobrir com seu manto azul-estrela, toca-me.Tocar, ser tocado ou tocarmo-nos? Sigo assim, sendo tocada e tocando na maioria das vezes sem perceber que esse ato é contínuo em minha vida (um eterno ir e vir como um rosário de bênçãos onde cada conta representa sons, perfumes, gestos, saudades! Flor de Lótus, Ouro Preto, março de 2013.

Nessa narrativa de memórias é possível flagrar a constituição do sujeito na relação estreita com a cidade, tanto em seus aspectos materiais quanto imateriais. $\mathrm{O}$ sujeito que rememora expressa a cidade da forma como a capta, por meio de seus sentidos, permitindo ao leitor observar a sedimentação das experiências vividas no espaço urbano em suas sensibilidades. A memória, embora fragmentária e fugidia, abarcou clima, sabores, sons, paisagens, costumes, entremeados às construções arquitetônicas, instituições e manifestações culturais.

Tais memórias trazem consigo outros sujeitos, outras formas de interação com a cidade, seus bens de cultura material e imaterial. São relações para além da contemplação, embora ela esteja presente, inclusive evidenciando que aquele que rememora também compreende a cidade como objeto de contemplação, de admiração; o que traz indícios da construção social da imagem da cidade como monumento, atravessando esse sujeito de forma inteira.

No entanto, mesclam-se às visões contemplativas e saudosistas, fios de experiências outras, amálgamas de experiências formativas na relação com as culturas locais. A cidade, dessa forma, reveste-se de outros sentidos e não é tomada como objeto, mas como meio de interação entre as 
pessoas, da família e da comunidade, de constituição de sujeitos que dão vida aos costumes locais, ao mesmo tempo em que esses últimos reverberam em suas visões de mundo e sensibilidades, num movimento constante de (re)elaboração.

A cidade, no movimento de rememoração, revela-se constitutiva de experiências singulares, embora em diálogo com visões coletivas ou constituídas no coletivo. As memórias permitem, inclusive, outra cartografia da cidade, reveladora de locais ainda não contemplados ou marginalizados em detrimento daqueles considerados mais expressivos para a história e memórias dominantes.

Nesse movimento de partilha e de escuta das palavras do outro, o Primaveras foi se configurando como percurso de questionamento de sensibilidades que imputam rótulos à cidade e aos professores. $\mathrm{O}$ projeto foi se tornando uma pesquisa-ação que não objetivava uma transformação nas práticas escolares, mas na própria concepção de si mesmo. E, nesse percurso, caminhando juntos, fortalecíamos nossa autoestima tão abalada após greves, reconfigurávamos possibilidades de trabalho com e na cidade, uma cidade na qual conseguíamos reconhecer memórias plurais, muitas delas marginalizadas ou silenciadas nos conflitos que as hierarquizam.

Fomos também transgredindo normas socialmente configuradas, implícitas, tácitas, que acabam por nos excluir de certos ambientes e práticas. Ousamos ser protagonistas de práticas educacionais e formativas fruindo diversos ambientes da cidade e seus equipamentos urbanos. Certamente uma prática transgressora porque, muitas vezes, temos nossos direitos de fruição estética negados ou reprimidos, principalmente quando somos cobrados a aprender sobre determinados bens culturais, ao invés de sermos estimulados a nos relacionarmos com eles, a partir de nossas experiências.

Concluímos o percurso daquele ano de atividades com uma exposição no Salão Principal da Casa dos Contos de Ouro Preto - Museu e Centro de Estudos do Ciclo do Ouro, numa parceria solicitada pelo Museu Casa Guignard, a fim de promover maior visibilidade àquele trabalho que já reunia um denso material a ser exposto. Enquanto o Museu Casa Guignard se localiza na Rua Conde de Bobadela (antiga Rua Direita), na qual se concentram estabelecimentos comerciais que, em sua maioria, atendem ao público de turistas, a Casa dos Contos está na Rua São José (popular Rua dos
Bancos), centro comercial da cidade. Então, havia naquele deslocamento uma intenção política muito clara: tornar a exposição mais acessível ao morador da cidade, que transita cotidianamente por aquele espaço.

Atentos às demandas dos professores, solicitamos a flexibilização de horários de visitação, com agendamento prévio, a fim de contemplar turmas que estudavam no período noturno e nos primeiros horários da manhã. No mural interativo e no caderno de visitas da exposição foram registradas observações essenciais para nossas análises, uma vez que elas expressavam a abertura de possibilidades de ver, ser e estar na cidade. Frases que empregam os verbos sonhar, emocionar, reconhecer, recordar, reviver, estiveram muito presentes nos recados que nos foram deixados, dando indícios de sentimentos que foram despertados com o trabalho realizado.

Quanto aos professores do Primaveras, tanto suas falas quanto suas práticas dentro e fora da sala de aula têm sido reveladoras de mobilizações iniciadas naquela pesquisa-ação. Houve, inclusive, quem começasse a mobilizar a família para escrever um livro de memórias, por considerar esse movimento importante para a compreensão de suas trajetórias, para os processos de cicatrização de feridas e para a interação com as gerações descendentes.

A pesquisa-ação Primaveras Compartilhadas teve consequências na sala de aula e no ambiente escolar, sem que para isso precisasse negar o professor em sua inteireza. As memórias, temporalidades e espaços revisitados favoreceram uma visão mais ampliada de nós mesmos e do outro. Esse movimento não se esgota na sala de aula, assim como nós professores não nos limitamos a ela. Certamente, não voltamos para a escola com uma capacidade instrumental reciclada, voltamos, nas palavras de uma das professoras do Primaveras, "empoderados", simplesmente porque nos sentimos mais sujeitos na relação como outro.

\section{O canto da Odisseia e as narrativas docentes}

A proposta de pesquisa a princípio focalizava os processos de formação continuada dos professores de História, porém, com as disciplinas cursadas na Unicamp e a participação nos grupos de pesquisa Kairós e GEPEC, à concepção de formação bem como as possibilidades teóricometodológicas de pesquisa se ampliaram.

O grupo "Kairós, coordenado na época 
(2012-2015) pela professora, Maria Carolina Bovério Galzerani, contribuiu significativamente para conhecermos e estudarmos as obras de Walter Benjamin e Edward Palmer Thompson. Conhecemos, em Benjamin, um pensamento aberto (plural), livre de dogmas, com uma preocupação aguçada sobre o mundo em que vivia e um olhar sensível com os diferentes sujeitos, invisíveis na sociedade da sua época (finais do século XIX e início do XX). Por meio das leituras de suas obras, ressignificamos nossa concepção de história e memória.

As ideias de Thompson (1981) foram um diferencial para esta pesquisa, para refletir sobre formação ${ }^{6}$ continuada de professores de forma mais ampla, rompendo com os limites da formação escolar/acadêmica e profissional. $\mathrm{O}$ autor contribui para pensarmos sobre a importância de considerar os professores como sujeitos que se constituem historicamente, em suas experiências vividas, as quais são atravessadas pelos movimentos de tensão/distensão e pelas fronteiras da resistência, conflitos e contradições.

As leituras de Walter Benjamin e Thompson, as orientações da professora Carolina e a contribuição do professor Guilherme foram fundamentais para enxergarmos além da racionalidade instrumental circundante, pois aguçaram algumas questões adormecidas ao longo da minha trajetória docente, tais como: o problema da falta de diálogo ${ }^{7}$ e a perda das experiências entre os professores da Educação Básica no cotidiano escolar e nos cursos de formação continuada. Nesse sentido, as preocupações da pesquisadora voltaramse para alguns questionamentos: até quando deixaremos as experiências se extinguirem do nosso cotidiano? Até que ponto vivemos hoje a desarticulação das experiências dos professores? Onde as experiências dos professores podem se manifestar? Onde poderemos encontrar professores que ousem contar suas experiências? Os professores invocam suas experiências? O que os professores narram em seus processos formativos?

$\mathrm{Na}$ angústia de como realizar a pesquisa, entre o sono e a vigília, flagramos, em "sonho", um "relâmpago" passando pelo pensamento, o clarão abria-se para as exigências do agora ${ }^{8}$. Foi o momento do "despertar do sonho" diante de uma imagem que se formava num "lampejo, como uma constelação. [...] uma imagem, que salta". Eis a imagem da obra Odisseia, de Homero, surgindo esvoaçante e trazendo consigo uma possibilidade para a construção do caminho teórico- metodológico da tese. (BENJAMIN, 2006, p. 504).

A escolha da obra Odisseia conhecida como um patrimônio da humanidade, do autor Homero, datada do século VIII a.C., traduzida por Antônio Pinto de Carvalho, constituiu-se como um importante documento histórico (THOMPSON, 1981) para a construção coletiva dessa pesquisa. Embora pairassem muitas dúvidas acerca de como a Odisseia enquanto patrimônio 9 (Odisseia) poderia ser prenhe de possibilidades para propostas de formação de professores, no entanto, apostamos que essa obra literária seria um documento potencializador do processo de rememoração das experiências vividas dos professores.

Tive como base a estratégia usada por Benjamin que procurou a literatura como um meio para produzir imagens significativas sobre os movimentos culturais dos séculos XIX e XX. Igualmente, acreditamos na Odisseia como uma produção capaz de engendrar sensibilidades e estimular as memórias dos professores. Ao decidirmos trabalhar com essa literatura considerada patrimônio da humanidade, acreditamos que havíamos encontrado uma nova configuração para trazer as experiências dos professores ao embarcarem na arte de narrar as suas vidas. A obra Odisseia surgiu como alegoria e possibilidade de instigar as palavras dos professores.

O patrimônio ao ser lido como um documento não monumentalizado estabelece outra relação/ponte entre sujeito e objeto (THOMPSON, 1981). Documento que possibilita, por meio do diálogo entre sujeito e objeto, a produção de conhecimento histórico mais inventivo, plural e criativo (TOMPSON, 1981).

Estabelecemos outra relação com o patrimônio (Odisseia), aquela pautada na racionalidade estética (MATOS, 1990; GALZERANI, 2004, 2013a, 2013a) que possibilita estimular a percepção, capaz de produzir sentidos múltiplos, ou seja, que as experiências dos sujeitos possam ser ressignificadas na relação com o patrimônio como seres humanos inteiros, portadores de racionalidades, mas também de sensibilidades.

$\mathrm{O}$ projeto de formação construiu espaços para os professores ressignificarem suas experiências por meio da rememoração, recuperando a dimensão de seres humanos historicamente datados e que (in)diretamente alcançaria o fazer docente.

Foi possível desenvolver essa pesquisa porque encontrei um grupo de professores ${ }^{10} \mathrm{com}$ os desejos parecidos aos das pessoas que moravam na 
terra dos Feácios $^{11}$ (pessoas que se reuniam frequentemente no palácio do rei Alcino, para contar as suas histórias e ouvir as rapsódias dos diferentes povos inspirados pelos aedos) ${ }^{12}$. Os professores escolheram pseudônimos de forma a compor a tripulação que embarcou nessa viagem: Minerva, Galateia, Alice, Saturnino, Sherazade, Tessália, Cleópatra e Ariadne.

Com esse grupo de professores iniciamos a pesquisa-ação (ELLIOT; GERALDI, FIORENTINI E PEREIRA, 1998) em uma escola pública, na cidade de Londrina, no estado do Paraná, porém, os docentes eram provenientes de diferentes escolas.

Os encontros ocorriam semanalmente no espaço escolar, durante quatro meses. Dentre as atividades desenvolvidas ocorreram: palestras, teatro, rodas de conversa, leituras de textos científicos, leitura da obra Odisseia, rememorações coletivas com fotografias e objetos históricos sobre as histórias de vida de cada professor. Todas as atividades desenvolvidas partiram e/ou estavam articuladas com a leitura da obra Odisseia. As memórias foram o meio de reflexão das experiências vividas e os professores foram estimulados a (re) significar o vivido.

$O$ perfil de rememoração coletiva e individual dos professores nesta pesquisa implicou o questionamento profundo das suas histórias de vida e de práticas educacionais totalitárias, assentadas na visão instrumental que tem produzido irracionalidades no cotidiano da escola e disseminando violências nas relações educacionais. Rememorar, nesse sentido, trouxe o passado vivido dos professores articulado com o questionamento de práticas culturais no presente e, ainda, uma busca atenta à construção das direções ao futuro (BENJAMIN, 1985).

Durante os encontros com os professores, questionamos as práticas educacionais automatizadas, destituídas de sentidos mais plenos para cada sujeito e a mecanização das pessoas nos dias de hoje, a vida sendo regida pela esfera econômica e, consequentemente, a transformação dos sujeitos em mercadoria na modernidade. Assim, o projeto "O Canto da Odisseia e as Narrativas Docentes" configurou-se na reflexão de nossas práticas cotidianas. Trazemos um fragmento da narrativa da professora Alice para ser lida como mônada (BENJAMIN, 1984; GALZERANI, 2013c).

Ulisses pode ser comparado a nós professores, pois temos a possibilidade de experimentar todo o universo que estamos passando aos alunos, pois nos debruçamos durante muitos anos a estudar a história. Nós escolhemos essa disciplina como fonte de trabalho e estudo. Porém, devido à falta de tempo e materiais didáticos não tão interessantes, nossos alunos não têm essa experiência. Além disso, Ulisses, por mais que experimente do canto, se limita pelas amarras feitas por seus companheiros. Isso também acontece na vida dos professores, pois, mesmo tendo muito conhecimento e anos de experiência, nos amarramos muitas vezes e não conseguimos experienciar os temas estudados em sala de aula. [...] o tempo e as cobranças da coordenação são as amarras que me limitam na minha prática dentro de sala de aula. [...]

A narrativa da professora Alice foi escrita após a leitura do capítulo "O Canto das Sereias", da obra Odisseia que possibilitou a ressignificação do sujeito ao interagir com o patrimônio, a partir das suas experiências vividas.

A partir dessa narrativa e outras produzidas pelos professores foi possível debater acerca do tempo cronológico marcado pelos relógios (THOMPSON, 1981; 1987) atrelado à preocupação de Benjamin $(1985 ; 2007)$ sobre o desparecimento da experiência com o avanço do capitalismo e, em seu lugar, o surgimento de vivências que levam à exclusão do outro, à liquidação da memória. Lembrando que na concepção benjaminiana, a experiência é aquilo que passa de geração a geração, ao ser subtraído dos homens, outros modos passam a imperar como as vivências que são atitudes automatizadas, individualizadas e destituidoras de sentidos coletivos, ou seja, plenas de significados para todo o grupo e para cada um dos seus integrantes, como pudemos flagrar na narrativa da professora Alice.

Portanto, com o avanço da modernidade, na relação íntima com o capitalismo, passamos a vivenciar a crise (experiências empobrecidas). Modernidade produtora de tendências culturais, das quais o passado deixa de ser referência para os sujeitos, agravando, ainda mais, a devastação das tradições e das experiências situadas historicamente, sobretudo dos lugares de que cada sujeito fala e do qual produz conhecimento.

Em diálogo com os professores, debatemos o fato de que, tanto na escola, como na universidade, há uma tendência de destruição das singularidades das culturas locais, afetando nossas sensibilidades e degradando nossas percepções coletivas (GALZERANI, 2008). Conversamos sobre 
como eles percebiam essas situações em seu cotidiano e como poderíamos encontrar frestas para transformar essa realidade. Portanto, frente aos paradoxos da modernidade, buscamos durante nossos encontros, não deixarmos apagar as nossas trajetórias e o nosso lugar de sujeito da e na história.

Fomentados por tais reflexões, os professores produziram narrativas orais e escritas, que traziam à tona suas imagens da docência (re)significadas e partilhadas coletivamente, em uma leitura alegórica da obra Odisseia.

O grupo dos professores com quem partilhamos experiências nessa pesquisa, apesar de perceberem em seu dia a dia os fluxos fantasmagóricos, enxergam imagens ambivalentes da modernidade e por isso, buscam no tempo do agora operar nos entremeios, ora questionando práticas educacionais maquínicas, ora provocando microrresistências, ora buscando outras maneiras de se relacionar no presente, a contrapelo das tendências homogeneizadoras da modernidade.

Durante os encontros compreendi a dialética entre experiência e educação, na qual os professores não são sujeitos alheios à sua realidade, muito menos passivos, mas construtores de suas histórias pelas brechas da modernidade (THOMPSON, 2002).

Ao final do projeto formativo "O Canto da Odisseia e as Narrativas Docentes", não nos enxergávamos como seres autômatos, fragmentados, sem rosto ou marcas, mas ao longo do percurso de pesquisa constituímo-nos um grupo de professores que têm nome, visões de mundo, histórias singulares e, apesar das diferenças de formação acadêmica e de trajetórias de vida, conseguimos estabelecer diálogos profícuos e produzir conhecimentos histórico-educacionais pelo viés coletivo, bem como estimular outras memórias e saberes com a potencialidade dos professores de se enxergarem ora ouvinte, ora interlocutores.

Portanto, ousamos ultrapassar a tendência cultural do esquecimento. Esquecimento que faz de muitos processos formativos práticas maquínicas, refletindo na cultura do sempre-igual "que tende a fazer do professor e dos alunos de história seres desolados ou ainda 'des-solado', sem solo, sem chão, sem lugar de pertencimento no mundo [...]" (GALZERANI, 2004, p. 27).

\section{Olhares "outros" da paisagem de formação continuada}

Os projetos de pesquisas "Primavera
Compartilhadas" e o "Canto da Odisseia e as Narrativas Docentes", contemplam ambos as sensibilidades no campo de formações de professores, em diálogo com os autores Peter Gay, Walter Benjamin e Edward Palmer Thompson. Nesse sentido, compreendemos os professores tanto do ponto de vista social como psicológico, portador de sensibilidades e seres (in)completos (GALZERANI, 2008).

Assim, tivemos que alargar nossa visão de formação. Buscamos em Thompson tanto conceituar experiência quanto problematizar o seu afastamento do campo da educação (THOMPSON, 1981; 2002; BERTUCI et al., 2010) e em Benjamin (1989) reforçar a aposta na constituição coletiva de nossas experiências, apesar dos avanços da modernidade e dos desafios que esta impõe às experiências enquanto algo que nos toca, atravessa e produz sentidos plurais para nossa existência, como nos fala Jorge Larrosa (BONDIÁ, 2002).

Além disso, tais pesquisas convergiam para a produção de conhecimento por uma via coletiva, na relação com as experiências vividas, tendo os professores como sujeitos, e não como objetos, de tais pesquisas (GALZERANI, 2004; 2008; 2013a). Portanto, apostamos no trabalho colaborativo (de fazer pesquisa com os professores e não sobre os professores), ao mesmo tempo, em um trabalho autônomo e inventivo, com a potencialidade de promover a produção de conhecimento históricoeducacional, no qual o professor tem um papel de sujeito ativo.

Nesse sentido, os nossos projetos formativos não foram constituídos para se verificar algo quantitativamente, nem tampouco partiam de alguma meta a ser alcançada, mas para se configurarem em um movimento que nos permitisse trabalhar no seio de sensibilidades modernas prevalecentes, a contrapelo das tendências dominantes. Assim, buscamos romper com algumas tendências no campo da formação, notadamente aquelas mais voltadas à produtividade e os resultados imediatos ou imediatamente aplicáveis em sala de aula, bastante presentes em cursos de capacitação ou reciclagem, para que os sujeitos envolvidos pudessem (re)significar suas experiências, inclusive, docentes.

Procuramos, em nossas pesquisas, contribuir para o fortalecimento da imagem do professor enquanto sujeito ativo e intelectual em processo contínuo de formação. Formação como um processo inacabado, no qual o outro nos constitui, e que abarca um projeto humano emancipatório 
(GALZERANI, 2008).

Por isso, o caminho metodológico que percorremos envolveu tanto a pesquisa bibliográfica quanto a investigação coletiva de nossas próprias sensibilidades, consolidando um processo de pesquisa-ação docente peculiar, pois não tem como meta o emprego imediato dos conhecimentos produzidos pelo grupo no seu cotidiano profissional. Esperávamos primeiro que o que produzimos fizesse sentido para nossas vidas como um todo e nos permitisse tocar nossas experiências, mais uma vez, num sentido lato. A incorporação de elementos desse processo ao ambiente escolar/profissional não é uma meta, mas uma consequência.

Acreditamos que a pedra e a palavra enquanto patrimônios culturais são possibilidades frutíferas para propostas de formação de professores, quando concebidas como experiência singular e não simplesmente propiciadoras de um mero contato com imagens do passado monumentalizadas e, nesse sentido, exteriores aos sujeitos.

Esses bens culturais, que compõe o patrimônio da humanidade, foram tomados como documento em uma leitura a contrapelo das tendências dominantes da modernidade, em uma relação que incorpora ao conhecimento sua dimensão de subjetividade e de sensibilidade (GAY, 1988), sem deixar de capturar que tais dimensões são políticas, em sua dimensão ampla, e foram concebidos também como alegorias, potencializadores de um olhar outro, aberto à incorporação das demandas do presente, receptivo aos olhares e sensibilidades de sujeitos em outros espaços e tempos.

Pensamos que é possível que o patrimônio seja lido como um documento alegórico como possibilidade de expressar imagens conflituosas, ambivalentes, contraditórias, imersas, portanto, na historicidade. A alegoria, imersa na historicidade, busca outra leitura do patrimônio, uma prática que Filo de Alexandria chamou de allo (outro) agorien (dizer). Em uma leitura alegórica do patrimônio (pedra e palavra), sentido e história estão ligados, pois só há sentido na temporalidade. A alegoria denuncia a aparência de uma história totalizante e abre brechas para que os silêncios venham à tona, as experiências de alteridade e estética. Outras imagens lampejam, outras histórias surgem que rompem com a história linear, outras experiências de produção de conhecimentos históricos na relação com o patrimônio e as experiências vividas (BENJAMIN, 2007; 1994).
Nesse sentido, acreditamos que os sujeitos podem entrecruzar seus saberes e ultrapassar a dimensão da diluição do tempo, de espaço e os esfacelamentos das relações sociais, que muitas vezes preponderam na contemporaneidade. $\mathrm{O}$ que possibilita o fortalecimento da dimensão da cidadania dos sujeitos. Sujeitos que não apenas conservam seus patrimônios, mas, sobretudo, são hábeis em recriá-los, numa apropriação constante, a partir de questões mobilizadoras no presente e na relação com suas experiências vividas. Enfim, como nos inspira Edward Palmer Thompson (1981) num ato de produção de conhecimento histórico que possibilite uma dimensão dialógica, inventiva, plural, um encontro entre sujeitos e diferentes temporalidades. Fica o convite de pensarmos que o patrimônio pode ampliar outras possibilidades de diálogos, se deslocarmos as perguntas e a forma de nos relacionarmos e interagirmos com ele.

\section{Notas}

1 Sobre a constituição do GEPEC ver GERALDI, Corinta Maria Grisolia; FIORENTINI, Dario e PEREIRA, Elisabeth Monteiro de A. (Orgs). Cartografias do Trabalho Docente: $\operatorname{professor}(a)$ pesquisador(a). Campinas-SP: Mercado das Letras, 1998.

2 Sobre as diferentes abordagens de pesquisas narrativas trabalhadas no GEPEC ver: PRADO, Guilherme do Val Toledo; SOLIGO, Rosaura; SIMAS, Vanessa França. Narrativa em três dimensões (versão preliminar). Publicado em Anais do VI CIPA -2014; PRADO, Guilherme do Val Toledo, ROSA, Maria Inês Petrucci Rosa, SADALLA, Ana Maria Falcão de Aragão e GERALDI, Corinta Maria Grisólia. GEPEC: da educação continuada ao desenvolvimento pessoal e profissional em uma perspectiva narrativa. In: SOUZA, E.C., PASSEGGI, M.C. e ABRAHÃO, M.H.M.B. Pesquisa (auto)biográfica e práticas de formação. Natal (RN): EDUFRN/ São Paulo: Paulus, 2008; LIMA, Maria Emília Caixeta de Castro; GERALDI, Corinta Maria Grisolia e GERALDI, João Wanderley. O trabalho com narrativas na investigação em educação. Educação em Revista, Belo Horizonte, v. 31, n. 1, p. 17-44. mar./ 2015.

3 Maria Carolina Bovério Galzerani era historiadora, doutorada em História, e professora da Faculdade de Educação da Unicamp-SP. Faleceu em fevereiro de 2015.

4 Sobre tal pesquisa, ver: CUNHA, Nara Rúbia de 
C. Chão de Pedras, Céu de Estrelas: o MuseuEscola do Museu da Inconfidência, Ouro Preto, década de 1980. Dissertação (Mestrado em Educação) Faculdade de Educação, Universidade Estadual de Campinas, 2011.

5 A greve de 2010 durou 47 dias e a de 2011 durou 112, sendo a maior greve da história desse estado. Para saber mais, ver: http://www.sindutemg.org.br (último acesso em 31/03/2016).

6 Compartilho da concepção de Elison Paim de que, para além de formar professores, há um fazer-se professor, havendo um emaranhado de relações que se constituem quando os professores se relacionam com diferentes sujeitos e os constituem ao mesmo tempo. Para aprofundar a discussão pertinente à formação de professores, a referência para esse debate é a tese de doutorado: PAIM, Elison Antonio. Memórias e experiências do fazer-se professor. Tese (Doutorado) Faculdade de Educação, Universidade Estadual de Campinas, Campinas. 2005.

7 Quando passei a convidar os professores para construirmos juntos a pesquisa, esse fato ficou mais evidente.

8 Benjamin propõe uma concepção de história como processo aberto, não determinado antecipadamente, em que o inesperado e as oportunidades não previstas podem surgir a qualquer momento.

9 A Odisseia não é apenas um legado da Grécia, mas é considerado como patrimônio cultural da humanidade. Pode-se dizer que com essa obra, Homero, deixa como legado a possibilidade de se conhecer uma narrativa literária e conhecer histórias que fazem parte do patrimônio de todos os povos.

10 Fizemos o convite para os professores da rede estadual da cidade Londrina, no estado do Paraná, na área da História, porém, dois professores de literatura tiveram o interesse em participar, ampliando, assim, para outras áreas do conhecimento. Portanto, seis professores eram de história e dois de literatura, sendo estes, os protagonistas, junto comigo, dessa viagem.

11 Povos da Grécia que tinham os navios mágicos encontravam-se próximos aos deuses e guardavam alguns vestígios da idade do ouro. Eram, no entanto, considerados mortais. Ulisses foi o único que conheceu esses povos (HARTOG, 2004).

$12 \mathrm{O}$ aedo é a figura que canta as glórias dos reis e heróis, visto como um adivinho, com poder sobrenatural.

\section{Referências}

BENJAMIN, W.Origem do drama barroco alemão. São Paulo: Brasiliense, 1984.

Magia e técnica, arte e política: ensaios sobre literatura e história da cultura. $7^{\mathrm{a}}$ ed. São Paulo: Brasiliense, 1994. (Obras Escolhidas, v. 1)

Rua de mão única. 5a . ed. São Paulo: Brasiliense, 1995. (Obras Escolhidas, v. 2)

Charles Baudelaire, um lírico no auge do capitalismo. São Paulo: Brasiliense, 1989. (Obras Escolhidas, v. 3)

Passagens. Willi Bolle (Org. edição brasileira). Tradução de Irene Aron e Cleonice Paes Barreto Mourão. Belo Horizonte: Editora da UFMG/São Paulo: Imprensa Oficial do Estado, 2006.

BERTUCCI, L. M.; FARIA FILHO, L. M.; OLIVEIRA, M.A. T. Edward P. Thompson: história e formação. Belo Horizonte: Editora da UFMG, 2010 .

BONDIÁ, J. L. Notas sobre a experiência e o saber de experiência. Revista Brasileira de Educação. [online]. 2002, n. 19, p. 20-28.

CHOAY, F. A alegoria do patrimônio. São PauloSP: UNESP, 2006.

CORTESÃO, L. Investigação-acção - um convite a práticas cientificamente transgressivas. Recife, 2004. Texto de conferência promovida pelo Centro Paulo Freire- estudos e pesquisa.

CUNHA, N. R. Chão de pedras, céu de estrelas: o museu-escola do museu da inconfidência, ouro preto, década de 1980. Dissertação (Mestrado em Educação) Faculdade de Educação, Universidade Estadual de Campinas, 2011.

GAGNEBIN, J. M. Memória, história, testemunho. In: BRESCIANI, S.; NAXARA, M. Memória e (res) sentimento: indagações sobre uma questão sensível. 2. ed. Campinas: Editora da Unicamp, 2004. 
GALZERANI, M. C. B. $O$ Almanaque, $a$ locomotiva da cidade moderna: Campinas, décadas de 1870 e 1880. Tese (Doutorado em História), Instituto de Filosofia e Ciências Humanas da Universidade Estadual de Campinas, 1998.

—_. Memória, história e (re)invenção educacional: uma tessitura coletiva na escola pública. In: MENEZES, M. C. (Org.). Educação, Memória e História. Campinas-SP: Mercado das Letras, 2004.

Imagens entrecruzadas de infância e de produção de conhecimento em Walter Benjamin. In: FARIA, A. L.G.; DEMARTINI, Z. B.F.; PRADO, P. D. Por uma cultura de infância: metodologias de pesquisa com crianças. Campinas: Autores Associados, 2005.

Entrelazando conocimientos, memorias y práctivas educativas: una producción de culturas docentes. In: PARDO, M. B. L.; GALZERANI, M. C. B.; LOPES, A. (orgs.). Una "nueva" cultura para la formación de maestros: ¿Es posible?. Porto: Livpsic/AMSE-AMCE-WAER, 2008. p. 15-38.

Práticas de ensino em projeto de educação patrimonial: a produção de saberes educacionais. Revista Pró-Posições, Campinas, v. 24, n. 1 (70), jan./abr. 2013a.

Escola e Conhecimento de História e Geografia: uma disciplina acadêmica e a educação das sensibilidades. Revista Antíteses, Londrina, v. 6, n.12, p. 126-147, jul./dez. 2013b.

Imagens que lampejam: contribuições de Walter Benjamin para a produção de conhecimentos históricos. Encuentro de Saberes. Luchas populares, resistências y educación, Buenos Aires-Argentina, v. 1 , p. $53-64,2013$ c.

GAY, P. A experiência burguesa: da Rainha Vitória a Freud - A Educação dos Sentidos. São Paulo-SP: Cia das Letras, 1988.
GERALDI, C. M. G.; FIORENTINI, D.; PEREIRA, E. M. A. (Orgs.). Cartografias do trabalho docente: professor(a)-pesquisador(a). Campinas: Mercado das Letras, 1998.

LIMA, M. E. C.C.; GERALDI, C. M. G.; GERALDI, J. W. O trabalho com narrativas na investigação em educação. Educação em revista, Belo Horizonte, v. 31, n. 1, p. 17-44, mar./ 2015.

MATOS, O. Os arcanos do inteiramente outro. São Paulo: Brasiliense. 1989.

A melancolia de Ulisses. In: CARDOSO, Sergio \& NOVAES, Adauto (coord.). Os sentidos da paixão. São Paulo, Companhia das Letras. 1988. p. 141-157.

MEIRIEU, P. Apprendre de la ville: à l'intersection de l'espace et $\mathrm{Du}$ temps. In: Rencontre nationale des classes de ville. Paris, Le 30 mai, 2001. (Disponível em www.meirieu.com)

PAIM, E. A. Memórias e experiências do fazer-se professor. Tese (Doutorado) - Faculdade de Educação, Universidade Estadual de Campinas, Campinas. 2005.

PRADO, G. V. T.; SOLIGO, R.; SIMAS, V. F. Narrativa em três dimensões (versão preliminar). Publicado em Anais do VI CIPA -2014.

SILVA, H. R. Rememoração"/comemoração: as utilizações sociais da memória. Revista Brasileira de História, v. 22, n. 44, 2002.

THOMPSON, E. P. A miséria da teoria ou um planetário de erros. Rio de Janeiro: Zahar, 1981.

A formação da classe operária inglesa. Rio de Janeiro: Paz e Terra, 1987.

_. Os românticos: a Inglaterra na era revolucionária. Rio de Janeiro: Civilização Brasileira, 2002.

\section{Sobre os autores}

Cyntia Simioni França é Doutora em Educação pela Faculdade de Educação da Universidade Estadual de Campinas. Mestre em História Social pela Universidade Estadual de Londrina. Graduada em História. 
Pesquisadora do Grupo de mestrado em Ensino, linguagens e suas tecnologias (UNOPAR).

Nara Rúbia de Carvalho Cunha é Doutora e mestre em Educação pela Faculdade de Educação da Universidade Estadual de Campinas, graduada em História pela Universidade Federal de Ouro Preto, especialista em História e Cultura de Minas Gerais pela Pontifícia Universidade Católica de Minas Gerais.

Guilherme do Val Toledo Prado é Professor Livre-Docente da Faculdade de Educação da UNICAMP. LivreDocente em Educação Escolar pela Unicamp. Realizou estágio pós-doutoral pelo Departamento de Didáctica e Tecnologia Educativa da Universidade de Aveiro (Portugal). Possui doutorado em Linguística Aplicada, mestrado e graduação em Educação pela Universidade Estadual de Campinas.

Recebido em novembro de 2016.

Aprovado em fevereiro de 2016. 